\title{
Corrigendum: Commentary: Arginine Vasotocin Preprohormone Is Expressed in Surprising Regions of the Teleost Forebrain
}

OPEN ACCESS

Approved by:

Frontiers in Endocrinology

Editorial Office,

Frontiers, Switzerland

*Correspondence:

Jasmine L. Loveland

jloveland@orn.mpg.de

Specialty section:

This article was submitted to

Neuroendocrine Science,

a section of the journal

Frontiers in Endocrinology

Received: 21 March 2018

Accepted: 22 March 2018

Published: 06 April 2018

Citation:

Loveland JL and Hu CK (2018) Corrigendum: Commentary: Arginine Vasotocin Preprohormone

Is Expressed in Surprising Regions of the Teleost Forebrain.

Front. Endocrinol. 9:157. doi: 10.3389/fendo.2018.00157

\section{Jasmine L. Loveland ${ }^{1 *}$ and Caroline K. Hu ${ }^{2,3}$}

${ }^{1}$ Behavioural Genetics and Evolutionary Ecology Research Group, Max Planck Institute for Ornithology, Seewiesen, Germany, ${ }^{2}$ Department of Organismic and Evolutionary Biology, Howard Hughes Medical Institute, Harvard University, Cambridge, MA, United States, ${ }^{3}$ Department of Molecular and Cellular Biology, Howard Hughes Medical Institute, Harvard University, Cambridge, MA, United States

Keywords: arginine vasotocin, arginine vasopressin, nonapeptides, preoptic area, hypothalamus, teleost, amygdala

\section{A corrigendum on}

Commentary: Arginine Vasotocin Preprohormone Is Expressed in Surprising Regions of the Teleost Forebrain

by Loveland JL, Hu CK. Front Endocrinol (2018) 9:63. doi: 10.3389/fendo.2018.00063

In the original Commentary article on page 1 , the last name of a co-author of the article that was commented on was misspelled as "Winston" instead of "Winton." The authors apologize for the mistake. This error does not change the scientific conclusions of the Commentary in any way.

The original article has been updated.

Conflict of Interest Statement: The authors declare that the research was conducted in the absence of any commercial or financial relationships that could be construed as a potential conflict of interest.

Copyright $\odot 2018$ Loveland and Hu. This is an open-access article distributed under the terms of the Creative Commons Attribution License (CC BY). The use, distribution or reproduction in other forums is permitted, provided the original author $(s)$ and the copyright owner are credited and that the original publication in this journal is cited, in accordance with accepted academic practice. No use, distribution or reproduction is permitted which does not comply with these terms. 